\title{
Ueber künstlich erzeugte Rasselgeräusche zu Lehrzwecken.
}

\section{Von Dr. Wilhelm Hildebrandt, Privatdozent} in Freiburg i. Br.

Für Dozenten und Hörer bietet die Lehre von den verschiedenen Formen der Rasselgeräusche nicht unbeträchtliche Schwierigkeiten dar. Durch theoretische Erörterungen allein kann man die nichtklingenden, die klingenden und die metallisch klingenden Rasselgeräusche nicht so genau charakterisieren, daß der Student daraufhin am Patienten die eine oder die andere Form des Rasselns ohne weiteres richtig erkennen könnte. Es bleibt also nur die Möglichkeit übrig, am Kranken selbst die verschiedenartigen Rasselgeräusche zu demonstrieren.

Es ist bekannt, wie wechselnd und unbeständig Rasselgeräusche sind, wie ein Hustenstoß oft alle katarrhalischen Geräusche zum Verschwinden bringt und die Demonstration vorzeitig unterbricht. Vor allem aber ist zu bedenken, daß der Student im Anfang nicht richtig erfaßt, was er hören soll; er hält Rhonchi oder vielleicht Reibegeräusche, welche das Stethoskop auf der Haut des Patienten hervorruft, für das ihm demonstrierte Rasselgeräusch, und dieser verhängnisvolle Irrtum bleibt eingewurzelt für Jahre bestehen. Endlich wäre noch darauf hinzuweisen, daß jede Demonstration von Rasselgeräuschen für den Kranken - und es handelt sich dabei oft um dekrepide Menschen - äußerst belästigend ist. Schon dieser Umstand läßt es wünschenswert erscheinen, durch geeignete Vorbildung der Studierenden eine Abkürzung der zur Auskultation erforderlichen Zeit zu ermöglichen.

Wir bedürfen deshalb einer Vorrichtung, die es uns gestattet, dem Studenten die Erscheinungen, welche er nachher am Kranken hören soll, in einwandfreier Weise so zu demonstrieren, $\mathrm{da} \beta$ er sie, eventuell auch ohne Zuhilfenahme des noch ungewohnten Stethoskops, wahrnehmen kann.

Bei der Herstellung eines derartigen Phantoms stölit man auf gewisse Schwierigkeiten. Bläst man Luft durch ein enges Rohr in die Tiefe eines mit Flüssigkeit gefüllten Gefäßes hinein, so werden durch die aufsteigenden Luftblasen bekanntermaßen klingende Rasselgeräusche hervorgerufen. Auf die Art der Flüssigkeit kommt es dabei nicht an, auch bei Verwendung von Sputum habe ich klingende Rasselgeräusche erzielt. Nimmt man ein Gefäß mit unregelmäßigen, rauhen Wänden, so kann man auch damit kein einwandfreies Rasseln von nichtklingendem Charakter erzielen, auch in diesem Falle herrscht der klingende Charakter vor.

Im besonderen hängt die Klangfarbe der klingenden Rasselgeräusche und die eventuelle Beimischung metallischer Erscheinungen von der Größe des im Wassergefäße eingeschlossenen Luftraumes ab. In einem zu $2 / 3$ bis $3 / 4$ gefüllten Reagenzglase von etwa $1,6 \mathrm{~cm}$ Durchmesser und $15 \mathrm{~cm}$ Länge kann man durch die aufsteigenden Luftblasen Rasselgeräusche erzeugen, welche durchaus den am Krankenbett beobachteten klingenden Rasselgeräuschen entsprechen, wobei die Größe der Luftblasen maßgebend ist für die Entstehung von groß-, mittel- oder kleinblasigen Rasselgeräuschen.

Bei Benutzung eines nur teilweise gefüllten Meßglases von etwa $2,6 \mathrm{~cm}$ Weite und etwa $28 \mathrm{~cm}$ Höhe bekommen wir metallisches 
Rasseln, dessen Klangfarbe, bzw. Tonhöhe je nach der Füllung des Meßglases mit Wasser wechselt. Der metallische Charakter ist am deutlichsten, wenn möglichst wenig Wasser (etwa $3,5 \mathrm{~cm}$ hoch) eingefüllt ist, und verschwindet nach und nach, wenn das Gefäß gefüllt wird. ${ }^{1}$ )

Auskultieren wir nicht, wie bisher am Wassergefüße e (vgl. Abbildung), sondern am Gummiballon (bei d), so hören wir stets metallisches Rasseln,

einerlei ob wir nach der Art unserer Versuchsanordnung beim Auskultieren an dem engen, fast ganz gefällten Reagenzglaseklingendes Rasseln oder an dem weiten, wenig gefüll ten Mebglase metallisches Rasseln erwarten müßten.

Um nicht klin. cende Rasselgeräusche hervorzurufen, habe ich zwischen das zuführende Luftrohr (b) und die Wand des Wassergefäßes (e) ein Leinenbeutelchen von der Größe eingeschaltet, daß seine Falten sich sowohl der Wand des Luftrohres wie der des Wassergefäßes einigermaßen anlegten. (Das Leinenbeutelchen ist in der Abbildung mit $c$ schematisch angedeutet worden. Das Wassergefäß (e) sei ganz mit Wasser ge füllt. Schickt man mittels eines Gebläses Luft durch das unten am besten mit einer engen Oeffnung versehene Röhrchen (b), so werden durch die imWasser aufsteigenden Luftblasen typische, n ich t klingende Rasselgeräusche erzeugt, welche je nach der Weite des Luftröhrchens oder, was das Gleiche ist, nach der Größe der Luftblasen den Charakter von groß-, mittel- oder kleinblasigen Rasselgeräuschen aufweisen. Als Gebläse genügt ein solches, wie es zur Aufblähung des Magens verwendet wird; doch sollte der Ballon (d) nicht zu klein sein, da sonst die Schönheit der oben erwähnten metallischen Erscheinungen, soweit sie am Ballon hörbar sind, beeinträchtigt wird.

Das die Luft zuführende Rohr (a) habe ein Lumen von etwa $0,5 \mathrm{~cm}$ Durchmesser, eine untere Oeffnung (bei b) von $0,15 \mathrm{~cm}$, vorausgesetzt daß man mittelblasiges Rasseln erzielen will. Um nichtklingende Rasselgeräusche hervorzurufen, bedient man sich am besten zur Luftzufuhr eines Ureterenkatheters, da bei Verwendung eines Glasrohres, wie ich es eben beschrieben habe, klingender Charakter der Geräusche erzeugt werden kann durch Mitschwingen der Luft im Lumen des Glasrohres.

Aber selbst bei Beachtung dieser Vorsichtsmaßregel gelingt es nicht immer, Rasselgeräusche von nichtklingendem Charakter rein darzustellen. Wenn das Wassergefä nicht mehr ganz mit Wasser gefüllt ist und die Luft aus dem Gebläse unter zu hohem D ruck einströmt, mischen sich den nichtklingenden Rasselgeräuschen auch solche von klingendem Charakter bei, aber nicht in dem Maße, daß es für die Demonstration störend wirkt; der nichtklingende Charakter herrscht bei weitem vor.

Der um das Luftrohr herumzuwickelnde Leinenbeutel muß so groß sein, daß seine Falten den Raum zwischen dem Luftrohr und der Wand des Wasserbehälters zu einem großen Teile ausfüllen. Bedient man sich, wie es zur Erzeugung nichtklingender Rasselgeräusche das Zweckmäßigste ist, eines Reagenzglases, so ist ein Leinenbeutel von $2,6 \mathrm{~cm}$ Wandbreite zweckmäßig; man steckt das Luftrohr in das Lumen des Beutels hinein und wickelt den Beutel möglichst ungleichmäßig, aber recht locker um das Luftrohr herum. Die Länge des Beutels entspricht der $\mathrm{Höhe}$ des Wassergefäßes.

Es lassen sich also an meinem Phantome alle Arten von Rasselgeräuschen demonstrieren; man hörtbei Benutzungdes Leinenbeutels am Wasserbehälter (e) nichtklingendes Rasseln; beim Fortlassen des Leinenbeutels am Wasserbehälter

1) Ein etwa $z u$ einem Drittel gefülltes bauchiges Gefäß mit glatten, reflektionsfähigen Wänden bietet besọders günstige $\mathrm{Be}$ dingungen für die Erzeugung metallischer Rasselgeräusche; bei $\mathrm{Be}-$ nutzen eines sehr weiten zuführenden Luftrohres entstehen Geräusche, die den gurgelnden "Wasserpfeifengeräuschen“ bei Pyopneumathorax entsprechen. klingendes, unter Umständen auch metallisches Rasseln, am Ballon (bei d) stets metallische Geräusche.

Wird der Ballon (d) von der Hohlhand umschlossen, so tritt eine Verstärkung der Intensität der am Ballon hörbaren Rasselgeräusche ein.

In den mir zugänglichen Lehrbüchern der klinischen Untersuchungsmethoden finde ich nichts, was Aehnlichkeit hätte mit den lier mitgeteilten Beobachtungen, und ich habe auch bei mündlichen Erkundigungen, die ich bei Kollegen und bei meinen Hörern einzog, nicht erfahren können, daß an anderen Universitäten ähnliche Phantome zu Lehrzwecken bellutzt werden. Mir selbst haben sie in propädeutischen Kursen gute Dienste geleistet, und ich hielt es deshalb für angebracht, kurz darüber zu berichten. 